DOI https://doi.org/10.15589/znp2021.2(485).5

УДК 681.5:[681.7+004.93]

\title{
APPLICATION OF COMPUTER VISION TO INCREASE THE EFFICIENCY OF TRANSITIONAL GAS COMBUSTION PROCESS INSIDE THE BOILER
}

\section{ЗАСТОСУВАННЯ ЗАСОБІВ КОМП'ЮТЕРНОГО ЗОРУ ДЛЯ ЗБІЛЬШЕННЯ ЕФЕКТИВНОСТІ ПЕРЕХІДНОГО ПРОЦЕСУ ЗГОРАННЯ ГАЗУ ВСЕРЕДИНІ КОТЛА}

\author{
Tymur S. Arzikulov \\ ORCID: 0000-0002-6774-2477 \\ student.kpi.ta01@gmail.com \\ Yulian Ye. Hrudzynskiyj \\ jug@sonettele.com \\ ORCID: 0000-0001-9220-0621; \\ Oleksandr S. Bunke \\ 0000-0002-7945-7040; \\ alex@bunke.com.ua
}

\author{
Т. С. Арзікулов, \\ магістр
}

Ю. Є. Грудзинський,

старший викладач кафедри автоматизації

теплоенергетичних процесів

\section{О. С. Бунке,}

канд. техн. наук,

доцент кафедри автоматизації

теплоенергетичних процесів

\author{
National Technical University of Ukraine "Igor Sikorsky Kyiv Polytechnic Institute”, Kyiv \\ Національний технічний університет України «Київський політехнічний інститут імені Ігоря Сікорського», м. Київ
}

\begin{abstract}
Purpose. The article proposes an approach using computer vision algorithms for the process of increasing the combustion efficiency of a gas torch in an industrial boiler. Method. More than $60 \%$ of the world's energy is produced by burning liquid / solid / gaseous fuels. Most of the planet's fuel resources are depleting, so combustion processes need to be optimized. Gas boilers are one of the most common ways to generate heat energy. The combustion of gases is accompanied by the emission of electromagnetic waves in various ranges (infrared, visible, ultraviolet), the characteristics of which depend on the composition of the gas, the degree of its combustion, and the combustion temperature. Results. The combustion of a gas torch in a boiler occurs at high temperatures, making it impossible to measure its characteristics directly. Indirect measurement leads to a large inertia of the control system. Computer vision systems can perceive electromagnetic radiation emitted during combustion directly in the form of an image. Acquisition of high-precision and informative images requires the use of special multispectral cameras. Having carried out a spectral analysis of the obtained image, we obtain a spectral characteristic, which is characteristic for a certain state of the flame. Flare characteristics are variable and require constant identification. Flare characteristics are identified in a steady state using auxiliary signals (temperature in the furnace, oxygen content in flue gases, flame stability, flame brightness). Scientific novelty. In the steady state, the flame combustion mode is optimized, which is determined by the high temperature in the furnace at a constant gas flow rate. When the optimum point is reached, the corresponding spectral characteristic is assigned to it. In the process of further regulation, when the reference for the gas flow rate is changed, the air / oxygen supply will not change according to the proportional law, but to ensure the corresponding optimal spectral characteristic. Practical importance. The use of fuzzy controllers based on the analysis of the spectral trace of the torch makes it possible to increase the speed of the control system, but it requires a lot of computing power for image processing and analysis of the characteristics. The system is a complex structure, it makes high demands on the qualifications of operating and maintenance personnel.
\end{abstract}

Key words: computer vision; spectral analysis; thermography; combustion; optimization; fuzzy control; multispectral cameras; gas boilers; energy.

Анотація. Метою даної роботи є виявлення можливості застосування засобів комп'ютерного зору та регулювання на основі аналізу спектрального сліду факела для оптимізації процесу згорання газів у котлах ТЕС та пришвидшення протікання перехідних процесів у разі зміни режиму чи навантаження. Для досягнення поставленої мети вирішувалися такі завдання: дослідження та аналіз наявної науково-методичної бази щодо регулювання процесу горіння газо-повітряної суміші в котлах та наукової бази щодо вивчення характеристик процесу горіння; дослідження можливості використання методів комп’ютерного зору для оптимізації зазначеного 


\section{ЕЛЕКТРОЕНЕРГЕТИКА, ЕЛЕКТРОТЕХНІКА ТА ЕЛЕКТРОМЕХАНІКА № 2 口 2021}

процесу. Об'єктом дослідження роботи є система подачі газо-повітряної суміші в топку котла. Предметом дослідження є система регулювання подачі газо-повітряної суміші в топку котла.

Методика. Дослідження проводилось на основі застосування загальних методів теорії автоматичного управління та нечіткого регулювання. Застосовувалися методики комп'ютерного зору, а саме отримання спектральних та інших характеристик зображення, методики визначення меж об’єктів, методики термографії та спектрографії.

Результати. Наукова новизна використаних методів керування полягає в наступному: вперше запропоноване використання регулювання процесу подачі газо-повітряної суміші на основі аналізу спектрального сліду факелу ще не використовувалося. У нашому дослідженні висловлюється ідея застосування засобів комп'ютерного зору для керування процесом спалення палива, а також концепція спалювання палива 3 низьким надлишком кисню. Практична значимість. Очікувані результати від впровадження системи такі: зниження часу протікання перехідних процесів, можливість використання екстремальних режимів горіння, можливість отримання додаткової інформації про якість горіння та склад димових газів, а отже й самого палива. Також використання засобів комп’ютерного зору дозволить отримати інформацію про стабільність та площу факела, що підвищить якість та безпеку роботи котлоагрегатів.

Ключові слова: комп’ютерний зір; спектральний аналіз; термографія; горіння; оптимізація; нечітке регулювання; мультиспектральні камери; газові котли; енергетика.

\section{ПОСТАНОВКА ЗАДАЧІ}

Незважаючи на зростання прагнення світу до використання відновлюваних джерел електроенергії, зменшення викидів в атмосферу, усунення теплових та інших забруднень, теплова електроенергетика досі займає перше місце серед усіх джерел електроенергії у світі. Якщо звернутися до статистики вироблення електроенергії у світі, то можна побачити, що частка теплової енергетики станом на 2018 рік становила 63,5\% при загальній генерації 25 398,01 млрд кВт*год (рис. 1).

Якщо переглянути історію виробництва електроенергії, можемо помітити тенденцію до зменшення частки теплової енергетики, проте вона є недостатньо великою для того, щоб говорити про занепад цієї галузі у найближче десятиліття. Можливо, ця галузь буде процвітати ще не одне десятиліття, особливо з огляду на те, що світова потреба в енергії щороку зростає.

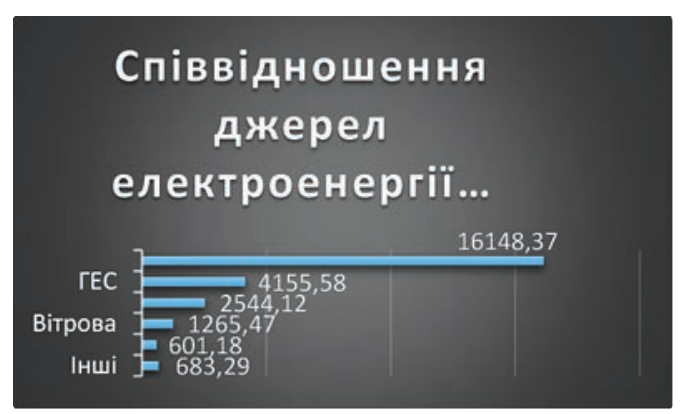

Рис. 1. Співвідношення джерел електроенергії Примітка* Джерело: https://knoета.ru

\section{АНАЛІЗ ОСТАННІХ ДОСЛІДЖЕНЬ І ПУБЛІКАЦЙ}

Основою теплоенергетичного технологічного процесу є спалювання горючої речовини - вугілля, мазуту, газу, біомаси. Найбільш екологічним з наведених видів палива $є$ природний газ, адже під час його спалення утворюється найменше продуктів згорання, зокрема, утворюється лише вода та двоокис вуглецю. Крім екологічності, розповсюдженість газових котлів порівняно iз твердопаливними спричиняє відносна простота транспортування газу, низька ціна, менші витрати на обслуговування газових котлів (зменшення затрат на очистку внутрішніх поверхонь котла, очистку димових газів).

3 огляду на розповсюдженість даного технологічного процесу (спалення газу) обираємо його предметом даної статті.

Регулювання процесу згорання палива традиційно відбувається трьома способами, а саме:

- регулюванням подачі палива;

- регулюванням подачі повітря (для твердого палива);

- регулюванням подачі палива й повітря.

У першому випадку горіння відбувається за допомогою так званого вторинного повітря, тобто повітря, подачу якого ми не регулюємо та яке потрапляє в котел під дією створюваного там розрідження. Другий випадок стосується лише твердих видів палива, тому в рамках цієї роботи він нас не цікавить. Останній - третій - випадок $є$ складнішим за перший, проте саме він є об'єктом нашого інтересу, адже, якщо ми маємо на меті оптимізацію технологічного процесу, можна одразу говорити про непридатність регулювання подачі газу. Основні причини цього можна виявити, розглянувши аналітичну модель котла.

У першому наближенні на температуру всередині котла, а отже й на теплоту, що може бути передана теплоносію, впливає лише кількість спалюваного газу. Однак у другому наближені варто брати до уваги такі фактори, як:

- температура та маса повітря, що надходить в котел;

- розсіювання теплоти в навколишньому середовищі;

- температура димових газів;

- якість змішування газо-повітряної суміші тощо. 
3 огляду на наведені фактори стає очевидним, що задля підвищення ефективності роботи котла необхідно використовувати регулювання подачі газо-повітряної суміші через горілки. При цьому, як правило, в промислових котлах первинне повітря, що подається разом з газом, попередньо нагрівається за допомогою димових газів.

Змішування повітря й газу є важливим показником горіння, адже саме воно визначає ефективність згорання газу. Саме тому варто використовувати технічні та методологічні засоби, що дозволяють оптимізувати цей процес. До таких засобів належать горілки з попереднім змішуванням газо-повітряної суміші та метод низькочастотних пульсацій факела, що забезпечуються пульсацією витрати газу й повітря [1].

Крім того, від ефективності горіння газу залежить також його яскравість та спектральна характеристика, на яку впливає наявність продуктів неповного згорання та домішок.

Перш ніж розглядати можливості створення системи регулювання на основі сучасних технологій, коротко розглянемо традиційні методи регулювання, а саме:

- пропорційний метод;

- пропорційний метод з адаптивним регулятором.

Під час використання пропорційного методу в регулятор, що керує контурами газу та повітря, або в два роздільних регулятора, що пов'язані між собою пропорційною залежністю, записуються коефіцієнти пропорційності подачі газу та повітря, що визначаються шляхом вирішення стехіометричних рівнянь горіння газу. Перевагами цього методу є простота та надійність, випробувана часом. Серед недоліків методу варто зазначити неможливість зміни коефіцієнтів пропорційності співвідношення газо-повітряної суміші при зміні якісного складу газу, а також необхідність враховувати функціональні залежності витрати газу/повітря до ходу регулюючих клапанів.

Системи пропорційної подачі із адаптивними регуляторами є більш сучасними й складними, вони дозволяють з часом змінювати коефіцієнти співвідношення подачі суміші. До недоліків таких систем належить необхідність проходження певного часу, перш ніж буде зібрана відповідна статистика, що дозволить усунути невідповідність.

Водночас на заході вже було висунуто та реалізовано концепцію згорання палива 3 низьким надлишком повітря, основною проблемою реалізації якої була непостійна якість палива (газу, вугільного/ торф'яного пилу), яку було важко відстежити в промислових умовах. Відповідно, виникла необхідність оперативного збору інформації про проходження процесу згорання палива, яка до цього збиралась опосередковано за допомогою вимірювання температури в котлі та рівня кисню в димових газах. Проте застосування сучасних технологій, а саме комп'ютерного зору, дозволило вирішити цю проблему [2].

\section{ВІДОКРЕМЛЕННЯ НЕ ВИРІШЕНИХ РАНІШЕ ЧАСТИН ЗАГАЛЬНОЇ ПРОБЛЕМИ}

Основною невирішеною частиною проблеми було безпосереднє визначення ступеню згорання палива за зображенням факела. У вже наявних методиках регулювання подачі газо-повітряної суміші використовуються параметри, що пов'язані із процесом згорання за допомогою певної нелінійної функції. Зокрема, це яскравість факела та його стабільність.

Використання регулювання за спектральною характеристикою вимагає достатньо великих розрахункових потужностей для аналізу зображення.

\section{МЕТОДИ, ОБ'ЄКТ ТА ПРЕДМЕТ ДОСЛІДЖЕННЯ}

Дослідження проводилося за допомогою аналітичних методів та вивчення наукової та методологічної бази з таких розділів, як термографія, спектрографія, комп'ютерний зір, нечітке регулювання. Об’єктом дослідження є система регулювання подачі газо-повітряної суміші в топку газового котла, предметом дослідження виступає безпосередньо процес горіння та обробки зображення горіння, отриманого за допомогою відеокамери.

\section{ОСНОВНИЙ МАТЕРІАЛ}

Для регулювання процесу згорання газу в цій роботі пропонується використовувати методи комп'ютерного зору, нечіткого регулювання, статичної оптимізації та спектрометрії/термографії. Більшості із нас з курсів фізики та хімії відомо про деякі особливості горіння речовин, рідин та газів. Цими особливостями $є$ різна температура горіння, що зумовлюється вивільненням теплової енергії внаслідок реакції розщеплення й окислення молекул, та різність кольору факела, що утворюється під час горіння (рис. 3). Остання властивість зумовлюється спектральними властивостями речовин і може охоплювати як інфрачервоний, так і ультрафіолетовий діапазон. Наприклад, двоокис вуглецю під час нагрівання генерує випромінювання в діапазоні 4,3 мкм, водяна пара та аміак - в діапазоні 2,5-3 мкм, водень та метанол проявляють спектральні характеристики в діапазоні ультрафіолетового випромінювання. Водночас синій колір газу під час горіння зумовлюється незначною кількістю окису вуглецю [3]. Проте зняття спектральної характеристики факелу і виявлення окремих складників ускладнюється турбулентними потоками, що проходять всередині. Отже, спостерігаємо динамічність розподілу та інтенсивності випромінювання в тілі факелу [4-5].

Для отримання більш повної інформації про проходження процесу горіння необхідно отримувати інформацію у різних спектрах, основними з яких $\epsilon$ видимий та ближній інфрачервоний спектр. Відповідно, виникає потреба у використанні спеціалізованих мультиспектральних камер [6]. 


\section{ЕЛЕКТРОЕНЕРГЕТИКА, ЕЛЕКТРОТЕХНІКА ТА ЕЛЕКТРОМЕХАНІКА № २ 2021}

Прикладом такої відеокамери є камера німецької компанії JAILtd cepiï GO [7] (рис. 2). Обговоримо переваги серії GO.

Малі розмір і вага. Камери цієї серії мають розміри 29х29x41.5 мм (без урахування кріплення об'єктива) і вагу менше 50 грамів, що дозволяє розміщувати їх в обмеженому просторі.

Висока швидкість зйомки. Використання сучасних і високопродуктивних CMOS-сенсорів дозволяє камерам серії GO забезпечувати високу швидкість зйомки, тим самим розширюючи галузь їх застосування. Наприклад, камера GO-5100-PGE 3 гігабітним інтерфейсом забезпечує швидкість зйомки 107 кадрів / с при роздільній здатності 5.1 Мп.

Висока якість зображсння. У 5-Мп моделях камер серії GO використовуються сенсори 3 досить великим розміром пікселя. Це забезпечує високу чутливість і велике співвідношення «сигнал / шум». На додаток технологія глобального затвора, аналогове посилення, вбудований LUT і інші функціональні особливості дозволяють отримати якість зображення, що перевершує очікування для камер такої цінової категорії.

Різноманітність інтерфейсів. Камери серії GO випускаються з різними сучасними цифровими інтерфейсами, що включають такі стандарти, як USB 3.0, GigabitEthernet, CameraLink тощо. Усі інтерфейси забезпечують живлення камери за допомогою інтерфейсного кабелю, що дозволяє скоротити кількість додаткових кабелів.

Промислове виконання. Камери серії GO виконані в міцному металевому корпусі і багаторазово випробувані на стійкість до вібрацій $10 \mathrm{~g}$ і ударних навантажень $80 \mathrm{~g}$, що дозволяє максимізувати їхню здатність протистояти суворим умовам промислової експлуатації. Середній час напрацювання на відмову становить більше 200000 годин.

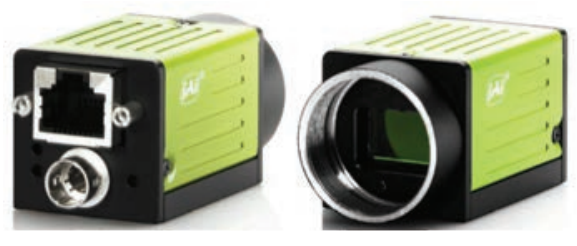

Рис. 2. Вигляд промислової відеокамери GO-5100-PGE

За умови визначеності газу та можливості фіксувати спектральні сліди усіх продуктів горіння, яскравості факелу, стабільності горіння ми можемо аналізувати якість проходження процесу згорання палива, а отже, й регулювати цей процес шляхом збільшення чи зменшення пропорції подачі повітря. Звісно, як і в будь-якій адаптивній системі, де виконується пошук оптимальних параметрів, тут необхідно застосовувати певні обмеження, а саме обмеження у вигляді нерівностей типу більше-або-дорівнює. Таким обмеженням є кількість кисню в димових газах, що не дає збільшити подачу повітря надмірно за кількість, необхідну для згорання газу, та функція стабільності факела, яка не має опускатись нижче певної межі.

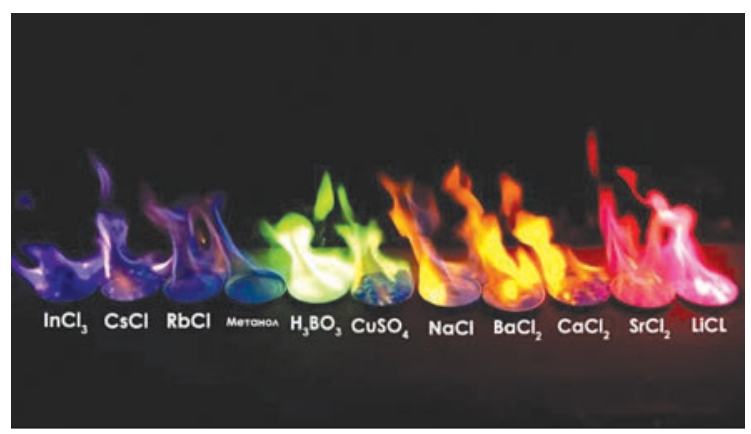

Рис. 3. Наочне зображення спектральних характеристик речовин

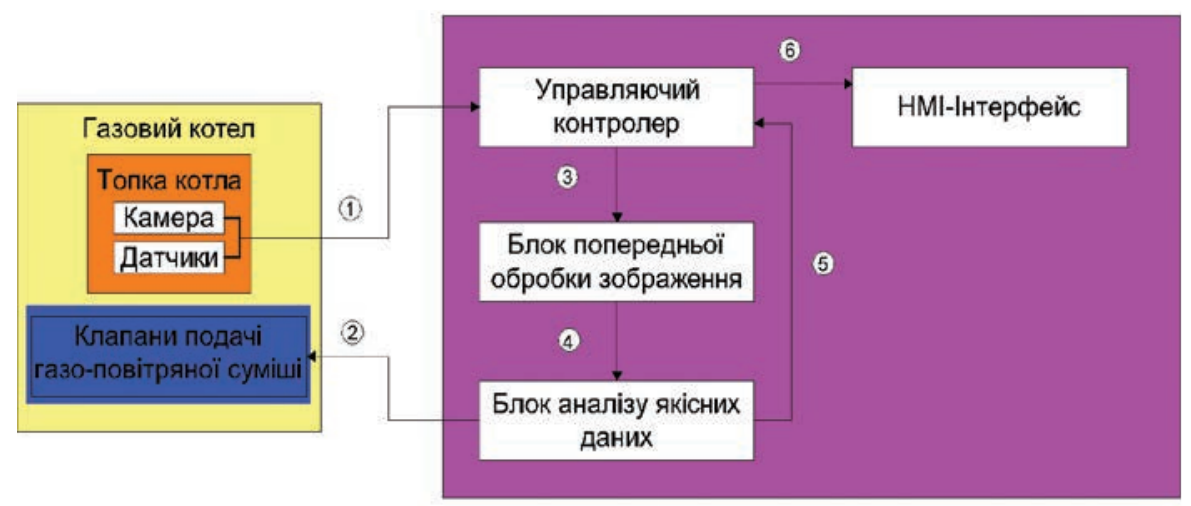

Рис. 4. Структура інтелектуальної системи керування з використанням нечіткого блоку аналізу відеосигналу Опис структури (рис. 4):

1 - дані, ше фіксуються відеокамерою, і поточні параметри котла;

2 - управління станом вентилів подачі газу і повітря на форсунки котла;

3 - дані у вигляді дискретної послідовності параметрів кольору і рівня відеосигналу $w(t)$;

4 - попередньо оброблені (фільтрація, нормалізація) параметри $w^{*}$ (t) у вигляді гістрограми розподілу амплітуд сигналу

і кольору за спектром (нормовані);

5 - якісний сигнал виявленого прочесу стану горіння і ступінь впевненості класифікатора;

6 - поточні параметри установки для людино-машинного інтерфейсу (НМI) оператора та керуючі дї оператора. 
Окремим випадком є побудова системи регулювання подачі газо-повітряної суміші невизначеного газу. Тоді, крім спектральних властивостей і вмісту кисню у димових газах, необхідне введення додаткового параметру, що буде визначати ефективність роботи системи. Таким параметром є температура у топці котла. За умови невизначеності спектрального сліду газу у найбільш ефективному процесі згорання постає потреба у визначенні цього співвідношення, що простіше за все досягти за допомогою використання методів статичної оптимізації, тобто шляхом зміни подачі повітря при усталеній подачі газу ми можемо визначити найбільш ефективний режим і відповідну до нього спектральну характеристику.

Перейдемо безпосередньо до визначення структури такої системи.

Основним iї елементом, що дозволяє отримувати оперативну інформацію про процес згорання, $є$ відеокамера. Шляхом обробки зображення, яке вона фіксує, за допомогою математичних алгоритмів ми можемо визначити такі параметри, як середня яскравість зображення, дисперсія, гістограми зображення, границі об'єктів, інші похідні параметри. Отримуючи такі дані неперервно, ми можемо визначити пульсації факелу та визначити стабільність процесу спалення [8-9].

Варто відзначити, що отримання та обробка великих масивів інформації з відеокамер вимагає високої потужності обчислювальних пристроїв, адже чим більша якість зображення, тим більшим стає об'єм математичних операцій, які необхідно для нього провести. Зокрема, зображення, отримане з камери відеоспостереження, є двовимірним масивом векторів із одним, трьома або більшою кількістю параметрів (у випадку мультиспектральних камер), які необхідно обчислити. Ці обчислення можуть виконуватись безпосередньо на станції, що виконує регулювання, або можуть бути попередньо зроблені на окремих апаратних додатках, які оброблюють інформацію з камер та передають ії у систему керування.

Другим не менш важливим елементом системи є безпосередньо система керування, яке пропонується виконувати на основі нечітких регуляторів. Як такий нечіткий регулятор можна використати програмований логічний контролер UniStrem компанії Unitronics (рис. 5).

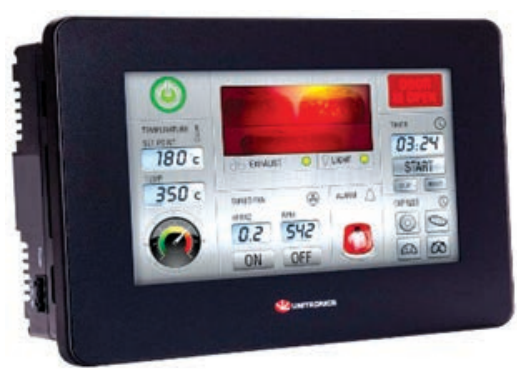

Рис. 5. Вигляд ПЛК UniStream 7 при роботі у складі робочої системи
Ця лінійка контролерів дозволяє використовувати мову Сі для створення керуючої програми з нечіткою логікою. До того ж ці контролери обладнано інтерфейсом Ethernet та USB для зв'язку з відеокамерою [10].

Також можливе використання аналітичних регуляторів, проте складність моделі та необхідність внесення до неї оперативних змін вимагатимуть ще більшої обчислювальної потужності.

Для попереднього прототипування промислової системи використовується мікрокомп'ютер RaspberryPi 3, що дає змогу швидко і дешево відпрацювати потрібні алгоритми.

Для створення нечітких алгоритмів керування можливе використання лінійної еталонної моделі [11]:

$$
\mathrm{x}_{\mathrm{m}}^{\prime}(\mathrm{t})=\mathrm{A}_{\mathrm{m}} \mathrm{x}_{\mathrm{m}}(\mathrm{t})+\mathrm{B}_{\mathrm{m}} \mathrm{r}(\mathrm{t})
$$

де

$\mathrm{x}_{\mathrm{m}}=\left[\mathrm{x}_{\mathrm{m} 1}, \mathrm{x}_{\mathrm{m} 2}, \ldots, \mathrm{x}_{\mathrm{mn}}\right]^{\mathrm{T}} \in \mathrm{R}^{\mathrm{n}}, \mathrm{r} \in \mathrm{R}, \mathrm{A}_{\mathrm{m}} \in \mathrm{R}^{\mathrm{n} * \mathrm{n}} \epsilon$

$\mathrm{B}_{\mathrm{m}} \in \mathrm{R}^{\mathrm{n}} \in$ матрицею Гурвіца у такій формулі:

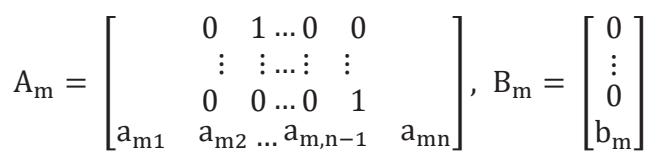

Завдання управління полягає в тому, щоб змусити стани нечіткої системи відстежувати стани еталонної моделі (1).

Третім елементом, що не є обов'язковим, є аналітична частина. Завданням цього компонента є визначення та реєстрація характеристик факела та палива. Ці дані можуть бути використані для оцінки ефективності роботи устаткування, визначення якості палива, що цілком можливо використати в комерційних взаємовідносинах.

\section{ОБГОВОРЕННЯ ОТРИМАНИХ РЕЗУЛЬТАТІВ}

Використання системи машинного зору дозволяє нам досягнути:

- якісно іншого визначення ступеня згорання газу;

- можливості визначення якісного складу газу в динаміці;

- можливості визначення стабільності факелу;

- можливості визначення форми та площі факелу.

До деяких недоліків майбутньої системи слід віднести:

- високу вартість спеціалізованих мультидіапазонних камер та розробки системи;

- складність;

- високі вимоги до обслуговуючого персоналу.

3 урахуванням високої собівартості, складності та підвищених вимог до обслуговуючого персоналу впровадження подібних систем є актуальним лише для великих промислових об'єктів, збільшення ефективності яких на 1-3\% після впровадження системи буде економічно виправданим.

\section{ВИСНОВКИ}

Важливим $€$ те, що використання систем комп'ютерного зору можливе не лише в системах 


\section{ЕЛЕКТРОЕНЕРГЕТИКА, ЕЛЕКТРОТЕХНІКА ТА ЕЛЕКТРОМЕХАНІКА № 2 口 2021}

газових котлів, але й в системах спалення твердого та рідкого палива та інших високотемпературних процесах. Тобто використання подібної системи здатне прискорити вирішення великого класу задач, пов'язаних 3 керуванням високотемпературними процесами з агресивними середовищами, що ускладнює або зовсім унеможливлює розміщення передавачів у камері згорання.

\section{REFERENCES}

[1] Vulis, L. A., \& Jarin, L. P. (1978). Ajerodinamika fakela [Torch aerodynamics]. Leningrad : Jenergija, 216, 62. [in Russian]

[2] Hirvonen, J., Lilja, R., Ikonen, K., \& Nihtinen, J. (1996). Image processing in combustion control. International journal of pattern recognition and artificial intelligence, 10(02), 129-137.

[3] Buckmaster, J. (1976). The quenching of deflagration waves. Combustion and Flame, 26, 151-162.

[4] Buckmaster, J. (1976). The quenching of deflagration waves. Combustion and Flame, 26, 151-162.

[5] Loboda, E. L., Rejno, V. V., \& Agafoncev, M. V. (2016). Primenenie termografii pri issledovanii processov gorenija [The use of thermography in the study of combustion processes]. Izdatel'stvo Tomskogo universiteta, 77. [in Russian]

[6] Victor, V. (2006). Research and testing of fuel oil combustion, using flame infrared thermography. URL: http://qirt.org/archives/qirt2006/papers/006.pdf (Last accessed: 17.03.2021).

[7] Baranov, P. S., \& Chirkunova, A. A. (2015). Televizionnaja kamera vidimogo i blizhnego infrakrasnogo diapazonov [Visible and near infrared television camera]. Izvestija vysshih uchebnyh zavedenij Rossii. Radiojelektronika, (4), 47-56. [in Russian]

[8] Go Series GO-5100C-PGE compact 5 MP area scan camera. URL : https://www.jai.com/products/go-5100c-pge (Last accessed: 17.03.2021).

[9] Klette, R. (2019). Komp'juternoe zrenie. Teorija i algoritmy [Computer vision. Theory and algorithms]. Moscow: DMK Press [in Russian].

[10] Berg, I. A., \& Porshnev, S. V. (2019). Metody analiza i transformacii izobrazhenij gorjashhego fakela $\mathrm{v}$ infrakrasnom diapazone jelektromagnitnogo spectra [Methods of analysis and transformation of images of a burning torch in the infrared range of the electromagnetic spectrum]. Cloud of science, 6(4), 550-564 [in Russian].

[11] UniStream ${ }^{\circledR} 7 "-$ PLC Controller With High Resolution HMI Touchscreen. (2021). URL: https://www.unitronicsplc.com/ unistream-series-unistream7/\#1451657921124-e6e0a431-3292 (Last accessed: 17.03.2021).

[12] Qi, R., Tao, G., \& Jiang, B. (2019). Fuzzy system identification and adaptive control. NY: Springer AG, 293.

\section{СПИСОК ВИКОРИСТАНОЇ ЛІТЕРАТУРИ}

[1] Вулис, Л. А., \& Ярин, Л. П. (1978). Аэродинамика факела. Ленинград : Энергия, 216, 62.

[2] Hirvonen, J., Lilja, R., Ikonen, K., \& Nihtinen, J. (1996). Image processing in combustion control. International journal of pattern recognition and artificial intelligence, 10 (02), 129-137.

[3] Buckmaster, J. (1976). The quenching of deflagration waves. Combustion and Flame, 26, 151-162.

[4] Buckmaster, J. (1976). The quenching of deflagration waves. Combustion and Flame, 26, 151-162.

[5] Лобода, Е. Л., Рейно, В. В., \& Агафонцев, М. В. (2016). Применение термографии при исследовании процессов горения. Издательство Томского университета.

[6] Victor, V. (2006). Research and testing of fuel oil combustion, using flame infrared thermography. URL: http://qirt.org/ archives/qirt2006/papers/006.pdf (Last accessed: 17.03.2021).

[7] Баранов, П. С., \& Чиркунова, А. А. (2015). Телевизионная камера видимого и ближнего инфракрасного диапазонов. Известия высших учебных заведений России. Радиоэлектроника, (4), 47-56.

[8] Go Series GO-5100C-PGE compact 5 MP area scan camera. URL : https://www.jai.com/products/go-5100c-pge (Last accessed: 17.03.2021).

[9] Клетте, Р. (2019). Компьютерное зрение. Теория и алгоритмы. Москва : ДМК Прес.

[10] Берг, И. А., \& Поршнев, С. В. (2019). Методы анализа и трансформации изображений горящего факела в инфракрасном диапазоне электромагнитного спектра. Cloud of science, 6 (4), 550-564.

[11] UniStream ${ }^{\circledR}$ 7-PLC Controller With High Resolution HMI Touchscreen. (2021). URL: https://www.unitronicsplc.com/ unistream-series-unistream7/\#1451657921124-e6e0a431-3292 (Last accessed: 17.03.2021).

[12] Qi, R., Tao, G., \& Jiang, B. (2019). Fuzzy system identification and adaptive control. NY : Springer AG, 293.

(C) Арзікулов Т. С., Грудзинський Ю. Є., Бунке О. С. Дата надходження статті до редакції: 10.06.2021 Дата затвердження статті до друку: 29.06.2021 